\title{
Mapping in words: Standardizing cartographic terminology
}

Serena Coetzee ${ }^{\mathrm{a}, *}$, Amy L. Griffin ${ }^{\mathrm{b}}$, Barend Köbben ${ }^{\mathrm{c}}$, Petr Kubicek ${ }^{\mathrm{d}}$, Francis Harvey ${ }^{\mathrm{e}}$, Dalia E. Varanka ${ }^{\text {f }}$, Silvana P. Camboim ${ }^{g}$, Franz-Josef Behr ${ }^{\text {h}}$, Reese Plews ${ }^{\text {i }, ~ H a r o l d ~ M o e l l e r i n g ~}{ }^{j}$, Terje Midtb ${ }^{\mathrm{k}}$

${ }^{a}$ Department of Geography, Geoinformatics and Meteorology, University of Pretoria, Pretoria, South Africa, serena.coetzee@up.ac.za

${ }^{b}$ School of Science, RMIT University, Melbourne, Australia, amy.griffin@rmit.edu.au

${ }^{c}$ ITC, University of Twente, Enschede, The Netherlands, b.j.kobben@utwente.nl

${ }^{d}$ Department of Geography, Faculty of Science, Masaryk University, Brno, Czech Republic, kubicek@geogr.muni.cz.

${ }^{e}$ Leibniz. Institute for Regional Geography, Leipzig, Germany and Warsaw University, Warsaw, Poland, f_harvey@leibniz-ifl.de

${ }^{f}$ U.S.Geological Survey, Rolla, United States, dvaranka@usgs.gov

${ }^{g}$ Departamento de Geomática, Universidade Federal do Paraná, Brazil, silvanacamboim @ufpr.br

${ }^{h}$ Stuttgart University of Applied Sciences, Stuttgart, Germany, franz-josef.behr@hft-stuttgart.de

${ }^{i}$ Plews Consulting Co. Ltd., Tokyo, Japan, reese@plewsconsulting.co.jp

${ }^{j}$ Geography Dept, Ohio State University, Columbus, OH, USA, moellering.1@osu.edu

${ }^{k}$ Geomatics group, Dept. of Civil and Environmental Engineering, Norwegian University of Science and Technology, Trondheim, Norway,terjem@ntnu.no

* Corresponding author

Keywords: terminology, semantics, standardization, cartography

\section{Abstract:}

The International Cartographic Association (ICA) recently joined the Open Geospatial Consortium (OGC), an international consortium of more than 500 businesses, government agencies, research organizations, and universities. Their focus is on standardization towards the interoperability of geospatial data, applications and services "to make geospatial (location) information and services FAIR - Findable, Accessible, Interoperable, and Reusable” (OGC, 2021b). Subsequent to joining the OGC, four ICA Commissions (SDI and Standards, Cognitive Issues in Geographic Information Visualization, Open Source Geospatial Technologies, and Geospatial Semantics), as well as the Working Group on the Cartography Body of Knowledge, started discussions on how the ICA could contribute to the OGC. Standardization of cartography-specific terminology was identified as one of the areas where the ICA could make a contribution. The aim is to make cartographic terminology accessible to OGC members, who tend to be tech-savvy but are from different professional backgrounds with no or limited training in cartography, yet they often use maps or develop software for tools that display maps.

Today, it is common to work in multi-disciplinary teams whose members regularly speak a range of different native languages, and each discipline also has its own vocabulary or language. This can lead to unintentional misunderstandings and ambiguities. For example, portrayal is the English term for "presentation of information to humans" (ISO 19117:2012, 4.20). Among English-speaking cartographers, it refers to the presentation of geographic information on maps specifically. However, most non-native English speakers would not expect a working group that focuses on maps and symbology to be called portrayal, after the artistic use of the term. Nevertheless, this is the term used by the OGC Domain Working Group on Portrayal. OGC defines portrayal as "The presentation of information to humans, e.g., a map. In the context of the Web, portrayal refers to how data is presented for the user. Map portrayal, for example, is concerned with shape and color of symbols representing features, rules for displaying text labels, rules for showing/not showing symbols based on zoom extent, etc.” (OGC, 2021a).

An extensive list of cartographic terminology, translated into 14 languages, was published in 1973 (ICA Commission II, 1973). The development of this multi-lingual dictionary spurred the publication of single-language dictionaries in countries participating in its development (ICA Commission II, 1973). However, in the past 40 some years, the art, science, and technology of making maps has changed significantly. Some terms in the 1973 book are now obsolete (e.g., double line scriber, opisometer, stud register system), while new terms have emerged (e.g. interactive map, augmented reality, GIS). In 1997, a new, extended, edition was published, now in 25 languages (Neumann, 1997). There are also cartographic dictionaries in specific languages, e.g., in Dutch (Bos et al., 1991), Portuguese (IBGE, 2021), Czech (VÚGTK, 2021), Croation (Lapaine et al., 2009), English (United States Army Topographic Command, 1969), German, English and French (Bundesamt für Kartographie und Geodäsie, 1997), French and English (Nédélec, 1978). 
In addition to these cartographic dictionaries, standards development organizations in the field of geospatial information maintain glossaries of the terms used in their standards. For example, the Terminology Maintenance Group (TMG) of ISO/TC 211, Geographic information/Geomatics, harmonizes terms and definitions in the ISO 19100 series of standards (Coetzee et al., 2018) and publishes them as a multi-lingual glossary of terms (MLGT) that is freely available on the Resources page of the ISO/TC 211 website (ISO/TC 211, 2021a). Subsets of the glossary have been translated into 15 languages (ISO/TC 211, 2021b). The Open Geospatial Consortium (OGC) glossary draws from a number of sources and from familiarity with the language and agreed terms of the OGC Technical Committee (OGC, 2021a). Another glossary by the Open Source Geospatial Foundation (OSGeo) (OSGeo, 2021) aims to "collect over the years geo* related terms in a multi-language style to facilitate reading/writing in other languages" (OSGeo Wiki Contributors, 2021). Finally, general purpose dictionaries and textbooks also provide definitions for cartographic terms.

In order to better understand how current sources support communication about maps among people from different professional backgrounds and languages, we collected and compared cartographic terms and their definitions in nine languages, namely Afrikaans, Czech, Dutch, English, German, Japanese, Norwegian, Portuguese, Slovak and Spanish. To choose terms for comparison, each author wrote down the list of terms that they would use to explain the following tasks to a professional from another discipline:

- $\quad$ how to find a walking route from the station in Florence/Firenze (Italy) to Hotel Ester using OpenStreetMap www.openstreetmap.org.

- how to use the World Health Organization's dashboard https://covid19.who.int/ to compare the COVID-19 statistics between two countries.

For the terms that we used most frequently in the above explanations, we located definitions from a range of sources and languages. Next, we compared the terms and definitions within a specific language to the term and definition in the latest cartographic dictionary (Neumann, 1997) and considered whether the term and its definition should be revised or harmonized to be better understood by our specific target audience of tech-savvy professionals from different backgrounds and native languages.

The potential misunderstanding of portrayal shows that communication always involves context and semantics. Dictionaries provide definitions for anyone, not for a specific context, but they sometimes explain how a term is used in a specific context. Textbooks can be directed at a specific professional or cultural context, but the target audience is typically new to the topic. Communication among people from different professional backgrounds and languages requires a different kind of solution than communication among people from the same or similar professional background who speak different native languages. Current cartographic dictionaries (ICA Commission II, 1973; Neumann, 1997) are aimed at the latter, but with this initiative we are interested in the former.

Based on an analysis of the terms and definitions that we collected, we conclude that the need to revise terminology already defined in the multi-lingual cartographic dictionaries has limited potential for contributing to the work of the OGC. However, new terms emerged in the past few decades (e.g., map tile). In some cases, the terms may have been defined in a general context (e.g., pan, zoom) but should also be made cartography specific. Similarly, there is room for improvement by adding terms and definitions in those languages not currently included in the multi-lingual cartographic dictionaries, i.e., most languages spoken in Africa and Asia and/or the languages spoken by most people in Africa and Asia. These definitions could help authors of general-purpose dictionaries in those languages to also list cartographyspecific definitions, e.g., for terms such as symbol, classification, generalization or layer. Finally, even though much of the existing terminology does not need to be revised, converting the multi-lingual cartographic dictionary into an online searchable glossary would already make it much more accessible to tech-savvy professionals from different professional backgrounds and native languages. Furthermore, developing ontologies based on existing terminology and making them available in the Resource Description Framework (RDF) or Web Ontology Language (OWL) would make cartographic knowledge machine-readable and ready for consumption in the Semantic Web, thereby helping position cartography as part of the broader information society. Going forward, the following should be considered:

- Which of the above recommendations should be taken forward?

- Should the recommendations be addressed collectively or as individual projects/initiatives?

- Who should be the target audience? Only technical experts involved with the OGC or a wider audience?

- Which role(s) should the ICA and its Commissions play, e.g., facilitator, developer and/or sponsor?

- Which stakeholders may have an interest to provide input and feedback or contribute as facilitator, developer and/or sponsor?

- We plan to arrange a workshop late in 2021 where these questions can be discussed with the wider ICA community, including those who are responsible for providing cartographic terminology in languages of the respective member countries, so that a way forward can be proposed. 


\section{References}

Bos, E., Geudeke, P., Ormeling, F., Sijmons, A., and Willems, G. (eds.) (1991). Kartografisch woordenboek (English: Cartographic dictionary). Nederlandse Vereniging voor Kartografie. Online edition at https://kartoweb.itc.nl/kartografischwoordenboek/ (accessed 5 May 2021).

Bundesamt für Kartographie und Geodäsie (1997). Fachwörterbuch Benennungen und Definitionen im deutschen Vermessungswesen mit englischen und französischen Äquivalenten (English: Technical Dictionary. Terms and Definitions as used in Surveying and Mapping in Germany). First Edition. Frankfurt: Bundesamt für Kartographie und Geodäsie.

Coetzee S, Plews R, Brodeur J, Hjelmager J, Jones A, Jetlund K, Grillmayr R, Wasström C (2018). Standards - making geographic information discoverable, accessible and usable for modern cartography. In: Service Oriented Mapping Changing Paradigm in Map Production and Geoinformation Management, edited by Jürgen Döllner, Markus Jobst and Peter MU Schmitz. Springer, pp 325-344.

IBGE (Intituto Brasileiro de Geografia e Statistica) (2021). Dicionário cartográfico (English: Cartographic dictionary). Available at https://www.ibge.gov.br/geociencias/metodos-e-outros-documentos-de-referencia/vocabulario-eglossarios/16496-dicionario-cartografico.html?=\&t=sobre (accessed 16 April 2021).

ISO/TC 211, Geographic information/Geomatics (2021a). Website. https://committee.iso.org/home/tc211 (accessed 5 May 2021).

ISO/TC 211, Geographic information/Geomatics (2021b). Resources. https://committee.iso.org/sites/tc211/home/re.html (accessed 19 May 2021)

Nédélec, F. (1978). Glossaire de termes géographiques et de renseignements cartographiques: français-anglais, anglaisfrançais (English: Glossary of geographic terms and cartographic information: French-English, English-French). Institut Géographique National, Paris.

Neumann, J. (ed.) (1997). Enzyklopädisches Wörterbuch Kartographie in 25 Sprachen (English: Encyclopedic dictionary of cartography in 25 languages). K.G. Saur Verlag: Munich. doi:10.1515/9783110969115. ISBN 9783598107641 (2011 electronic facsimile ed.: ISBN 9783110969115).

OGC (Open Geospatial Consortium) (2021a). Glossary of Terms. https://www.ogc.org/ogc/glossary (accessed 5 May 2021).

OGC (Open Geospatial Consortium) (2021b). Website. https://www.ogc.org/ (accessed 5 May 2021).

OSGeo (Open Source Geospatial Foundation) (2021). OSGeo Glossary. https://osgeo.geolexica.org/concepts/ (accessed 5 May 2021).

OSGeo Wiki Contributors (2021). OSGeo Multilanguage Dictionary. https://wiki.osgeo.org/wiki/OSGeo_Multilanguage_Dictionary. (accessed 5 May 2021).

United States. Army Topographic Command, 1969. Dictionary of Mapping, Charting and Geodetic Terms. Map Division IV.

VÚGTK, 2021. Terminologický slovník zememerictvi, a katastru nemovitosti (English: Terminological Dictionary of Geodesy, Cartography and Cadastre) https://www.vugtk.cz/slovnik/index.php (accessed 16 April 2021). 